\title{
Mineral Waters, Electricity, and Hemlock: Devising Therapeutics for Children in Eighteenth-Century Institutions
}

\author{
ASHLEY MATHISEN* \\ Department of History, University of Guelph, Guelph, ON, Canada N1G 2W1
}

\begin{abstract}
The development of paediatric medicine as a formal field of medical specialisation is usually traced to the mid-nineteenth century at the earliest. While it is true that formal specialisation in children's medicine was not, on the whole, typical for eighteenth-century medical practitioners, many displayed a deep and lasting interest in the diseases of children, and were consequently eager to develop therapeutic practices which could be targeted at infants and children. This led to a variety of attempts at innovation, many of which benefitted from the co-operation of, and opportunities afforded by, institutions. By examining the efforts of several medical practitioners at the London Foundling Hospital and at the Dispensary for the Infant Poor, this article explores how eighteenth-century medical practitioners used their affiliations with institutions to address the problems of devising or adapting therapeutic practices and treatments for children. In tailoring medical practice to suit children and, more specifically, in using institutions to do so, medical practitioners were demonstrating that child patients required special consideration, that children's diseases could be managed medically and with the benefit of new approaches and methods, and that children's health, as a whole, was the province of medical practitioners.
\end{abstract}

Keywords: Children, Paediatrics, Medicine, London Foundling Hospital, Therapeutics, Institutions

On Saturday 17 March 1759 the sub-committee of the London Foundling Hospital recorded the following in their weekly minutes:

and it being also represented to this Committee according to the report of the Matron of the Infirmary that the Female Child No. 11372 was given over. And Mr Bromfield Surgeon of the Lock Hospital having at Mr Madan's recommendation seen the Child and he being of opinion that he can save the Poor Infant. Resolved: that the Child be sent to the Lock Hospital at Hyde Park Corner not only with a View to preserve her life but also to Try if any new Method of treating Venereal Complaints can be discovered more effectual

* Email address for correspondence: mathisen.ashley@ gmail.com

I would like to acknowledge the invaluable advice provided by Dr Margaret Pelling, Dr Erica Charters, Dr Alysa Levene and Professor Joanna Innes on earlier versions of this article. I am also indebted to the two anonymous referees for Medical History, who provided insightful comments and suggestions. 
to the preservation of the lives of Infants under such unhappy circumstances than what has been hitherto practiced in the Hospital. ${ }^{1}$

Thomasine Edmonton, 'Female Child No. 11372', was only one child among over 17,000 admitted to the Foundling Hospital in the eighteenth century, but the circumstances surrounding her medical treatment warrant closer examination. She was the first child to be formally exchanged between the Lock Hospital and the Foundling Hospital under a programme designed by the two institutions to cope with the problem of venereal disease in children. ${ }^{2}$ This collaborative arrangement was one of several steps taken by institutions like the Foundling, the Lock Hospital, and many of the London dispensaries to use the unique opportunities presented by an institutional environment to advance contemporary understandings of how disease impacted children, and to discover whether or not any new therapeutic practices could be conscripted into the ongoing struggle to ensure the good health of infants and children.

It is clear from cases such as Thomasine Edmonton's that the established chronology for the history of paediatrics in Britain requires some reappraisal. There has been a tendency, particularly in studies of children's hospitals, to equate the rise of paediatrics with the development of these hospitals from the 1850s onwards. ${ }^{3}$ The assumption behind this view is that, while eighteenth-century medical practitioners may have treated child patients occasionally, they were not engaged in any significant systematic approaches to the twin problems of child morbidity and mortality. At best, this assumption casts eighteenth-century medical practitioners as misguided forerunners to later paediatricians. Even historians of paediatrics, who tend to trace a much longer trajectory for medical interest in children, have suggested that the eighteenth century was a period of 'stagnation in the progress against childhood diseases'. ${ }^{4}$ This characterisation of the eighteenth

${ }^{1}$ London Foundling Hospital Sub-Committee Minutes (hereafter SCM), 17 March 1759, London Metropolitan Archives (hereafter LMA), A/FH/A/03/005/003.

2 Thomasine Edmonton was sent by the Foundling Hospital to the Lock Hospital on 19 March 1759. She returned two months later and was sent out to a nurse in the country, but spent the next few months being shuttled between the nurse, the Foundling Hospital infirmary, and the Lock Hospital. She died on 2 January 1760: General Register of Children, 27 January 1759, LMA, A/FH/A/09/002/003. By February 1761, fourteen children had been sent from the Foundling Hospital to the Lock Hospital for treatment: London Foundling Hospital General Committee Minutes (hereafter GCM), 4 February 1761, LMA, A/FH/A/03/002/007.

${ }^{3}$ While pre-1850 developments such as the Foundling Hospital, the Dispensary for the Infant Poor, and Bunnel's Universal Dispensary often receive some mention, usually as short-lived institutions which failed to endure, the emphasis in discussions of the development of hospital provision for children is generally on nineteenth-century institutions: Alfred White Franklin, 'Children's hospitals', in F.N.L Poynter (ed.), The Evolution of Hospitals in Britain (London: Pitman Medical Publishing Co., 1964), 103-21; Eduard Seidler, 'An historical survey of children's hospitals', in Lindsay Granshaw and Roy Porter (eds), The Hospital in History (London: Routledge, 1989), 181-97; Elizabeth M.R. Lomax, Small and Special: The Development of Hospitals for Children in Victorian Britain (London: Wellcome Institute for the History of Medicine, 1996); Jules Kosky, Mutual Friends: Charles Dickens and Great Ormond Street Children's Hospital (London: Weidenfeld \& Nicolson, 1989); Jules Kosky and Raymond J. Lunnon, Great Ormond Street and the Story of Medicine (London: Hospitals for Sick Children, 1991); Andrea Tanner, 'Choice and the children's hospital: Great Ormond Street Hospital patients and their families, 1855-1900', in Anne Borsay and Peter Shapely (eds), Medicine, Charity and Mutual Aid: The Consumption of Health and Welfare in Britain, c. 1550-1950 (Aldershot: Ashgate, 2007), 135-61.

${ }^{4}$ A.R Colón and P.A. Colón, Nurturing Children: A History of Pediatrics (Westport: Greenwood Press, 1999), 144. While other histories of paediatrics give some weight to the eighteenth century, the assumption that the nineteenth century marks a break with the past in terms of interest in paediatrics is fairly prevalent: John Ruhräh, Pediatrics of the Past (New York: P.B. Hoeber, 1925); Arthur F. Abt and Fielding H. Garrison, Abt-Garrison History of Pediatrics (Philadelphia: Saunders, 1965); George Frederic Still, The History of Paediatrics: The Progress of the Study of Diseases of Children Up to the End of the XVIIIth Century, reprint (London: Dawson's of Pall Mall, 1965). 
century obscures the work of many practitioners who sought to extend medical control over children's health, and to find new ways of combating disease in children.

Just as eighteenth-century medical practitioners need to be given a more prominent place in the history of paediatrics, so too do they need to be included to a greater extent in narratives of the history of childhood. While academic study of the history of childhood has expanded in leaps and bounds over the past several decades, a few key gaps in study remain to be filled. The history of childhood has largely been dominated by examination of the relationships between child, mother and father, often within the rubric of the history of the family. ${ }^{5}$ While the role of state intervention in the lives of children has also been explored, providing a counterpoint to an otherwise dominant focus on the family, other relationships have been comparatively neglected. ${ }^{6}$ Though the significant place of parents or guardians should certainly not be sidelined or overlooked, examination of how medical practitioners perceived and devised health care solutions for children provides an excellent means of circumventing over-emphasis on the place of the child within the family and the home. $^{7}$

Where it has been studied, the interaction between children and medical practitioners has typically been assessed within the context of the development of large children's hospitals from the nineteenth century onwards and the corresponding rise of paediatric medicine as a professional medical specialty. ${ }^{8}$ While historians have also examined eighteenth-century child-centred institutions, such as the London Foundling Hospital, and the medical work conducted there, a great deal more could be said about medical practice within institutions for children, and the connections between these hospital practitioners and the wider medical community. ${ }^{9}$ The details of eighteenth-century medical practice have been explored in greater detail through studies of specific therapeutic trends such as cold bathing, mineral waters, and electricity. ${ }^{10}$ What remains is to link medical interest in

\footnotetext{
${ }^{5}$ Much of this agenda has been determined by the location of the roots of the historiography of the history of childhood within family history. This focus, as established by Aries, Shorter, Stone and others, has been carried on in many respects by Linda Pollock. See: Linda Pollock, A Lasting Relationship: Parents and Children Over Three Centuries (London: Fourth Estate, 1987); Linda Pollock, Forgotten Children: Parent-Child Relations from 1500-1900 (Cambridge: Cambridge University Press, 1983).

${ }^{6}$ Ivy Pinchbeck and Margaret Hewitt, Children in English Society. Volume One: From Tudor Times to the Eighteenth Century (London: Routledge and Kegan Paul Ltd, 1969); Eric Hopkins, Childhood Transformed: Working-Class Children in Nineteenth-Century England (Manchester: Manchester University Press, 1994).

${ }^{7}$ Margaret Pelling, 'Child Health as a Social Value in Early Modern England', The Society for the Social History of Medicine, 1 (1988), 135-64.

${ }^{8}$ See (note 3$)$.

${ }^{9}$ R.H. Nichols and F.A. Wray, The History of the Foundling Hospital (London: Oxford University Press, 1935); Ruth McClure, Coram's Children: The London Foundling Hospital in the Eighteenth Century (New Haven: Yale University Press, 1981); Ruth McClure, 'Pediatric Practice at the London Foundling Hospital', Studies in Eighteenth-Century Culture, 10 (1981), 361-71; Alysa Levene, Childcare, Health and Mortality at the London Foundling Hospital, 1741-1800: 'Left to the Mercy of the World' (Manchester: Manchester University Press, 2007); Gillian Pugh, London's Forgotten Children: Thomas Coram and the Foundling Hospital (Stroud: Tempus Publishing, 2007).

${ }^{10}$ E.S. Turner, Taking the Cure (London, 1967); Noel G. Coley "“Cures Without Care": "Chymical Physicians" and Mineral Waters in Seventeenth-Century English Medicine', Medical History, 23 (1979), 191-214; David Harley, 'A sword in a madman's hand: professional opposition to popular consumption in the waters literature of Southern England and the midlands, 1570-1870', in Roy Porter (ed.), The Medical History of Waters and Spas. Medical History Supplement No. 10 (London: Wellcome Institute for the History of Medicine, 1990), 48-66; Simon Schaffer, 'The consuming flame: electrical showmen and Tory mystics in the world of goods', in John Brewer and Roy Porter (eds), Consumption and the World of Goods (London: Routledge, 1993), 489-526; Paul Elliott, "'More Subtle Than the Electric Aura”: Georgian Medical Electricity, the Spirit of Animation and the Development of Erasmus Darwin's Psychophysiology', Medical History, 52 (2008), 195-220; Paola Bertucci,
} 
children, and the institutional settings for many medical encounters between practitioners and children, with developing therapeutic practices. In making this connection, we can see how children's health provided the impetus for a great deal of medical investigation in the eighteenth century, and how institutions played a role in nurturing medical innovation and specialisation in children by providing the forums in which medical practitioners could see, touch, listen to, and treat child patients en masse.

For medical practitioners, the ability to treat child patients allowed them to tip the prevailing assumptions about childcare in their favour. As historians have suggested, the domestic environment was a crucial space for the medical treatment of children, and children typically received medical care in the home at the hands of mothers, nurses, and midwives. ${ }^{11}$ However, the expansion of institutional medical provision in London over the course of the eighteenth century considerably increased the chances that a child would, at some point during the course of his or her childhood, receive medical assistance through an institution, such as the general dispensaries, the smallpox hospitals, some of the voluntary hospitals, or through an establishment such as the Dispensary for the Infant Poor, which made particular provision for children. Thus we cannot ignore the role of the institution as a space where children received medical attention, and where medical practitioners could confront child patients. In doing so, they were attempting to expand their knowledge of children's diseases and disorders and to overturn the prevailing assumption that mothers, and women more generally, knew best with regard to children's health. Institutions provided practitioners with, among other things, the ability to test new methods on large groups of children, and to try innovative approaches on single child patients who could be closely observed over time. Significantly, all of this care could occur within the confines of the hospital, rather than in the family home, where the authority of the practitioner was compromised by the notion that women were the natural caretakers of children. The goal of practitioners, such as William Cadogan, who served as physician to the Foundling Hospital, was to ensure that 'the Preservation of Children become the Care of Men of Sense'. ${ }^{12}$ Hospital work provided Cadogan's 'man of sense' with the experience necessary to sell himself to the public as an authority on children's health, and many of his contemporaries used their institutional experience to similar ends.

The intent of this article is not to suggest that medical practitioners did not pursue innovative approaches in private practice, but rather that institutions provided unique spaces, and in many cases, a cooperative partnership conducive to medical efforts to further knowledge of the bodies and diseases of child patients. Private practice provided valuable experience, but it was limiting in terms of comparison between concurrent cases.

\footnotetext{
'Revealing Sparks: John Wesley and the Religious Utility of Electrical Healing', British Journal for the History of Science 39, 3 (2006), 341-62; Paola Bertucci, 'Therapeutic attractions: early applications of electricity to the art of healing', in Harry Whitaker, C.U.M Smith and Stanley Finger (eds), Brain, Mind and Medicine: Essays in Eighteenth-Century Neuroscience (New York: Springer, 2007), 271-83.

${ }^{11}$ A considerable body of research has been amassed on the subject of domestic medicine. Of this research, several studies have spoken directly to the medical care of children within the household: Ralph Houlbrooke, The English Family, 1450-1700 (Essex: Longman Group, 1984); Pollock, A Lasting Relationship, op. cit. (note 5); Helena M. Wall, "My constant attention on my sick child”: the fragility of family life in the world of Elizabeth Drinker', in James Marten (ed.), Children in Colonial America (New York: New York University Press, 2007), 155-67; Hannah Newton, "Very Sore Nights and Days": The Child's Experience of Illness in Early Modern England, c.1580-1720', Medical History, 55, 2 (2011), 153-82; Leigh Whaley, Women and the Practice of Medical Care in Early Modern Europe (Houndmills: Palgrave Macmillan, 2011).

12 William Cadogan, An Essay Upon Nursing and the Management of Children from their Birth to Three Years of Age (London 1748), 3.
} 
In addition, since eighteenth-century medical practitioners were invested in providing a counterpoint to the methods and alleged misconceptions of domestic medicine, the institution was a crucial vehicle, not only for amassing a body of knowledge through experience, but also for demonstrating that, in transporting medical care from the household to the hospital, the medical practitioner need no longer entirely compete with the power structures and authority of the domestic environment. As medical practitioners interested in children's health consequently argued, the diseases of children could only be fully understood if they were studied in a more systematic manner, and it was the institution that provided the most appropriate forum for this more systematic approach.

By examining the efforts of three medical men in particular, this article will explore how eighteenth-century medical practitioners, living and operating in an era prior to the development of children's hospitals, joined many of their contemporaries in using the opportunities afforded them by their affiliation with child-centred institutions to investigate the problems of devising or adapting for children therapeutic practices and treatments. At the London Foundling Hospital, the apothecary Robert McClellan conducted a trial between the years of 1759 and 1762 of the efficacy of mineral waters on various skin and eye conditions suffered by the hospital's children. His Foundling Hospital colleague, the physician William Watson, attempted to cure paralysis in a young girl in 1762 through the use of medical electricity. Lastly, in the 1770s, in the Dispensary for the Infant Poor, George Armstrong tested the effectiveness of hemlock on whooping cough in infants and children.

The objective in discussing these three cases is not to falsely obscure the differences between them. Indeed, their differences exemplify the varied nature of eighteenth-century medical practice and investigation. While McClellan's study involved some forty children, Watson's involved a single child. Similarly, while both McClellan and Watson discussed the children they treated by name, Armstrong's small whooping cough patients received no such distinction. The three medical practitioners in question also came from different backgrounds and approached their medical work in different ways based on personal inclination and the demands of the institutions they served. However, despite the ways in which they differed, these three cases shared several common elements which should not be overlooked. In the broadest sense, all three practitioners were motivated by a common desire to learn more about children's health, particularly since all three were affiliated with two London institutions devoted specifically to children. McClellan and Watson both worked for several years for the London Foundling Hospital, while Armstrong's career was largely spent toiling in his Dispensary for the Infant Poor. Both McClellan and Armstrong spent almost their entire careers with child patients, and Watson's twenty-five years at the Foundling Hospital ensured that children were a significant percentage of his patient load. These three men thus had a vested interest in learning new techniques to treat child patients. Their connection with children's health was, in short, more than a passing fancy, or the simple consequence of the patient group privileged by the institutions they served.

There are further commonalities linking these three studies. All three operated within a medical world that was increasingly disposed towards new ideas and the questioning of established wisdom, and all three participated in a changing milieu of medical practice, as medicine shifted from being an art or a craft to being an endeavour informed to a much greater extent by the methods of natural philosophy. ${ }^{13}$ Their attempts to develop new

\footnotetext{
${ }^{13}$ Susan Lawrence discusses this shift from medicine as art to medicine as science. As she makes clear, this was not a smooth transition, though it did inform how medical practitioners and the public viewed medical
} 
practices should be seen against this changing backdrop. All three studies also took place in institutions, and all three involved only child patients. In addition, all three practitioners made some effort to record their work, and to communicate their findings. Two of these three cases were published for public consumption, and the third case was detailed in the Foundling Hospital's records, providing a chronicle for future practitioners of the institution to draw upon.

While these three cases cannot, of course, be compared to modern clinical trials, they represent more than simple trial and error. In investigating how new therapeutic practices could be used on children, McClellan, Watson, Armstrong, and several of their contemporaries were demonstrating, with varying degrees of success, that child patients required special consideration, that children's diseases could be managed medically, and that children's health, as a whole, was the province of medical practitioners. These efforts to develop innovative approaches to providing medical treatment for children were thus representative of the larger efforts of practitioners to assert control and authority over medicine for children. Though McClellan, Watson, and Armstrong were not formally accredited paediatricians, as their nineteenth- and twentieth-century counterparts would become, their interest in children's health, and their practical investigations into therapeutics for child patients, set them apart from many of their colleagues, and marked them as children's doctors long before the term 'paediatrician' came into common use.

\section{The Meaning of Innovation}

As mentioned earlier, eighteenth-century medical practitioners, for obvious reasons, did not operate in a modern world of carefully controlled clinical trials. Yet their attempts to cure patients were also not as random as they might appear to the modern eye. Rather, eighteenth-century medical practitioners typically pursued innovation in the space between these two poles, sometimes leaning more towards systemic trials, and sometimes preferring simple quantification. On one hand, they could look to the example of James Lind's work on scurvy, or William Cadogan's smallpox inoculation trials, both of which used carefully delineated test groups. On the other hand, emerging out of the study of political arithmetic, there was a general drive in the seventeenth and eighteenth centuries to quantify health and disease as a means of arriving at ideally objective truths. ${ }^{14}$ The Foundling Hospital, for example, kept detailed records on whether its children were wet or dry nursed, and it was these mortality statistics, as well as the advice of influential governors such as Hans Sloane, that caused the hospital to largely abandon the practice of dry nursing, just as the hospital's support of inoculation owed a great deal to William Cadogan's in-house experiments with the procedure. ${ }^{15}$ Methods of quantification were readily seized upon by institutions like the Foundling Hospital which needed to publicly prove its mortality record, as well as by medical practitioners who wished for the authority conferred by successful practice made evident to the public. Despite the relative lack in the eighteenth century of controlled trials, as defined by modern medicine, medical practitioners, influenced by a medical culture increasingly disposed towards an empirical

\footnotetext{
'experimentation': Susan Lawrence, Charitable Knowledge: Hospital Pupils and Practitioners in EighteenthCentury London (Cambridge: Cambridge University Press, 1996), 301-10.

${ }^{14}$ Eighteenth-century efforts at quantification and knowledge gathering are well examined in: Andrea Rusnock, Vital Accounts: Quantifying Health and Population in Eighteenth-Century England and France (Cambridge: Cambridge University Press, 2002); Daniel R. Headrick, When Information Came of Age: Technologies of Knowledge in the Age of Reason and Revolution, 1700-1850 (Oxford: Oxford University Press, 2000).

15 Valerie Fildes, Wet Nursing: A History from Antiquity to the Present (Oxford: Basil Blackwell, 1988), 159-69.
} 
approach, did work to investigate new approaches in the context of a more systematic approach.

Though the pluralistic nature of therapeutics for much of the eighteenth century makes it difficult to draw a clear line between the utilisation of multiple and sometimes innovative remedies on one hand, and medical trials, or experimentation, on the other, it is possible to discern a method behind how practitioners approached new forms of medical practice. As mentioned earlier, this method was hardly systematic in the modern sense of a clinical trial, yet nor was it simply trial and error, or opportunistic experimentation. As Ulrich Tröhler has argued, eighteenth-century medical practitioners used two complementary approaches when assessing medical innovation. ${ }^{16}$ The 'assessment' approach evaluated the relative risk of harm to the patient and society, while the 'improvement and safety approach' focused on making the intervention safer from a medical point of view. Both elements can be seen in the case of Thomasine Edmonton. In sanctioning an innovative approach to her illness, the governors of the Foundling Hospital hoped to save her life, therefore considering the risks to the individual patient. They also hoped to gain knowledge which might make treatments for venereal disease safer for children, thereby saving the lives of future children.

Eighteenth-century medical practitioners were cautious in their use of experimentation in part as a consequence of burgeoning notions surrounding ethical medical practice. ${ }^{17}$ For John Gregory, an early theorist of medical ethics, the ideal physician was an educated and erudite practitioner who was able to balance monetary disinterestedness with 'a softness and gentleness of manner, a compassionate heart' ${ }^{18}$ Gregory's ideal view of the sympathetic medical practitioner also accorded with the rising culture of sensibility, and a notion of ideal masculinity derived from David Hume, who defined sensibility in part by linking its origins to a masculinity informed by tenderness and sympathy. ${ }^{19}$ The ideal medical practitioner was thus someone who approached his patients with a tenderness not compatible with calculated and risky experimentation.

Medical practitioners could also not afford to appear to be callous about the lives of their patients since their hopes of attaining the legitimacy conferred by professionalisation rested on the construction of 'legitimate' medical practice in opposition to the 'illegitimate' or 'irregular' practice of quacks, charlatans, and empirics. At the same time, however, they also sought to be innovative in their approaches and practices. Influenced by Enlightenment ideas about progress and the possibilities of science and medicine to contribute to the health and happiness of the population, eighteenth-century practitioners were comparatively more likely than their predecessors to attach a positive value to

\footnotetext{
16 Ulrich Tröhler, 'To assess and to improve: practitioners' approaches to doubts linked with medical innovations, 1720-1920', in Thomas Schlich and Ulrich Tröhler (eds), The Risks of Medical Innovation: Risk Perception and Assessment in Historical Context (London: Routledge, 2006), 20-37.

17 Andrew Wear, 'Medical ethics in early modern England', in Andrew Wear, Johanna Geyer-Kordesch, and Roger French (eds), Doctors and Ethics: The Earlier Historical Setting of Professional Ethics (Amsterdam, 1993), 98-130; Lisbeth Haakonssen, Medicine and Morals in the Enlightenment: John Gregory, Thomas Percival and Benjamin Rush (Amsterdam: Editions Rodopi, 1997); Laurence B. McCullough, John Gregory and the Invention of Professional Medical Ethics and the Profession of Medicine (Dordrecht: Kluwer Academic, 1998). 18 John Gregory, Observations on the Duties and Offices of a Physician and on the Method of Prosecuting Enquiries in Philosophy (London, 1770), 19.

${ }^{19}$ G.J. Barker-Benfield, The Culture of Sensibility: Sex and Society in Eighteenth-Century Britain (Chicago: University of Chicago Press, 1992), 135-37; McCullough, John Gregory, op. cit. (note 17), 113.
} 
innovative medical practice. ${ }^{20}$ The long decline of Galenism contributed to this state of affairs by suggesting that medical practice no longer needed to remain bound to the theories of the ancients, though the practice of medicine, of course, continued to owe a great deal to Galenic theory. ${ }^{21}$

Another contributing factor engendering a positive view of innovation was the debate concerning the relationship between nature and science, which encouraged the belief that nature could be understood and eventually mastered, and that a scientific approach to medicine could lead to advances in knowledge. ${ }^{22}$ In this context, it was increasingly assumed that the experience gained in medical practice would contribute new knowledge beyond what had been learned in the course of a practitioner's medical education, and that the desire for innovation was to be admired rather than distrusted.

In short, while eighteenth-century medical practitioners might not have been engaged in medical experimentation in the modern sense of controlled trials and well-established ethical standards, many undertook cautious innovation which often went above and beyond pluralistic therapeutics by using a relatively 'scientific' approach of multiple case studies, meticulous record keeping, and consolidation of results. It was this cautious innovation which directly contributed to medical efforts to establish knowledge and authority over children's medicine. Using the opportunities afforded them by their affiliation with institutions which cared for large numbers of children, the following three medical men attempted to apply innovation to the problems of children's diseases and disorders.

\section{Robert McClellan and the Mineral Waters from Powis Wells}

The chalybeate, or 'iron-rich' spring at Powis Wells had been frequented by those interested in its health benefits from at least $1721 .^{23}$ The well was located within the property purchased by the Foundling Hospital from the Earl of Salisbury in 1740 and, in subsequent years, the hospital made considerable use of the reputed therapeutic powers of the well's water. The water, when taken either internally or externally, was thought to be particularly useful in treating scrofula and eye conditions and, from 1759, Powis Wells water was used to treat the Foundling Hospital children for a variety of conditions, most of which involved the face, head, and eyes.

From August 1759 to February 1762 Robert McClellan, the hospital's apothecary, kept case studies of forty children treated with Powis Wells water. ${ }^{24}$ As resident apothecary to the hospital, McClellan was often commissioned by the administration to conduct trials of medical treatments or of medicines. In 1759 he was charged by the sub-committee to oversee a trial in which he was to administer water to six children and a small amount of beer to an additional six children, and then to observe the effects and report to the

\footnotetext{
${ }^{20}$ Spadafora has argued that faith in progress spread and took on new forms between the 1730s and 1780 s and that veneration of antiquity was more limited in the eighteenth century than has been assumed: David Spadafora, The Idea of Progress in Eighteenth-Century Britain (New Haven: Yale University Press, 1990), 8, 39.

21 The decline of Galenism was a long process occurring roughly between 1600 and 1800, though elements of Galen's approach persisted into the nineteenth century, making a narrative of straightforward decline unpersuasive: Owsei Temkin, Galenism: Rise and Decline of a Medical Philosophy (Ithaca: Cornell University Press, 1973); Andrew Wear, 'Medical practice in late seventeenth and early eighteenth-century England: continuity and union', in Roger French and Andrew Wear (eds), The Medical Revolution of the Seventeenth Century (Cambridge: Cambridge University Press, 1989), 294-320.

${ }^{22}$ Roy Porter, Enlightenment: Britain and the Creation of the Modern World (London: Allen Lane, 2000), 142.

23 Alfred Stanley Foord, Springs, Streams, and Spas of London: History and Associations (London 1910), 168.

24 'Apothecary's notes (in English) on treatment with the use of Powis Wells Water (1759-1762)', LMA, A/FH/A/18/009/001.
} 
General Committee. ${ }^{25}$ This particular trial may have been the root of the Powis Wells water study, since the committee subsequently ordered, 'that the Nurses or Servants do not on any pretence whatsoever give any Beer to the Children. This in order that the effect of the Childrens drinking Powis Wells Water may be more particularly observed' ${ }^{26}$ It is clear from these two studies that the hospital routinely provided practitioners like McClellan with opportunities to conduct basic trials of medicines or procedures, involving large numbers of children, who could be closely observed over time. These initiatives went some way towards creating, and then reinforcing, a partnership between hospital and medical practitioner that was highly conducive to the expansion of medical knowledge of children's health.

The timing of the Powis Wells water study was particularly significant since it occurred at the meeting point between two overlapping trends in therapeutics: one which could be utilised for a small cost, and the other which was less viable for the cash-strapped hospital. Prior to the mid-eighteenth century, mineral waters enjoyed massive popularity as a therapeutic treatment for a wide variety of ailments. In the second half of the century the preference for warm waters was superseded by a trend for cold water bathing and sea water, which was thought to be particularly useful in combating scrofula and skin complaints. Before the commencement of McClellan's study, the hospital had considered the benefits of sending children to Brighton for the sea water, but rejected the notion on the grounds that the expense was too high. ${ }^{27}$ The prohibitively high costs of sea bathing likely contributed to the hospital's decision to make use of the water from Powis Wells, which was also more conveniently accessible. The hospital's administration may also have been influenced by the numerous references in child-rearing texts to the particular benefits of cold baths for children. ${ }^{28}$ As William Buchan emphasised:

to young people, and particularly to children, cold bathing is of the last importance. Their lax fibres render its tonic powers peculiarly proper. It promotes their growth, increases their strength, and prevents a variety of diseases incident to childhood. ${ }^{29}$

McClellan's study included both variation and constant elements. The patients themselves varied considerably. Among the thirteen boys and twenty-seven girls in McClellan's study, there was a wide spread of ages. The youngest child, William Farnaby, was between the age of two and four when the study begun, while the oldest child, Elizabeth Jephson, was between the age of twelve and fourteen in 1760 when she was

\footnotetext{
25 SCM, 21 September 1759, LMA, A/FH/A/03/005/003. The sub-committee ordered the following week, 'that the Apothecary be as acute as possible in observing the progress of the most healthy Children newly come whilst they drink Water in order to make the Experiment of Beer at another time either in this Hospital or at Powis Wells', suggesting that the trial with small beer may have been postponed: SCM, 29 September 1759, LMA, $\mathrm{A} / \mathrm{FH} / \mathrm{A} / 03 / 005 / 003$.

26 SCM, 6 October 1759, LMA, A/FH/A/03/005/003.

27 GCM, 2 October 1753, LMA, A/FH/A/03/002/004. In 1787 the possibility of sending the children for sea bathing was again broached, but was rejected due to the weather and the season. GCM, 12 September 1787, LMA, A/FH/A/03/002/015.

28 John Locke, Some Thoughts Concerning Education (London 1693), 5. There was no eighteenth-century medical consensus on the value of cold baths for children, but cold baths were, in general, recommended by most medical practitioners: John Rendle-Short, 'Infant Management in the Eighteenth Century with Special Reference to the Work of William Cadogan', Bulletin of the History of Medicine, 34 (1960), 97-122. Cold baths as well as chalybeate waters were also recommended as a treatment for the excessive acidity of the stomach which children were thought, in particular, to suffer from: William Cullen, First Lines of the Practice of Physic...(London, 1783), 114-17.

${ }^{29}$ William Buchan, Cautions Concerning Cold Bathing, and Drinking the Mineral Waters... (London, 1786), 11.
} 
instructed to begin drinking the Powis Wells water for her scald head. However, constant elements were also built into the study. The amounts of water drunk by the children in the study were determined by the sub-committee, which stipulated that McClellan ensure that the children drink the water 'in small quantities at a draft' ${ }^{30}$ This qualification may have reflected contemporary debates on the value or harm of drinking large quantities of mineral waters. ${ }^{31}$ However, it might also have been indicative of the trend among medical practitioners to suggest that children required smaller doses of medicines than adults. The fact that it was the sub-committee, rather than McClellan, who determined some of the parameters of the study should not be seen as evidence of the superior control of laymen within the hospital. Many of the governors of the hospital were themselves medical men and, in any case, the relationship between the administration and the hospital's medical practitioners generally took the form of a mutually beneficial partnership. As a servant of the hospital, McClellan's position was tied to the hospital's success and, as such, he had as much to gain from a successful study as did the governors of the hospital. In addition, McClellan, as a medical practitioner whose career was dominated by the treatment of child patients, stood to benefit from any study which demonstrated a new and effective method of treating complaints in children.

The health conditions suffered by the children in the study were similar to those considered to be particularly receptive to the effects of mineral waters. Of the forty children in the study, nineteen were instructed to drink and/or wash with Powis Wells water to relieve scald head, and a further eleven were to use the water for some form of inflammation of the eyes. ${ }^{32}$ The case studies also detailed the use of the water to treat warts, 'the Evil', 'sore head' and 'a violent flux of sharp humours from the head'. These conditions, while lacking the high profile of smallpox, measles, or whooping cough, were particularly troublesome within the hospital. ${ }^{33}$ Indeed, the hospital's continual struggle to combat skin and eye conditions was a major factor encouraging the administration to commission McClellan's study of Powis Wells water. ${ }^{34}$

McClellan regrettably published no conclusions in print about his opinion concerning the medical value of the Powis Wells water, though he made detailed notes on each child's case, and he periodically reported on the progress of the trial to the hospital's subcommittee. ${ }^{35}$ Most of the cases detailed symptoms that continued to recur over time and, while some of the children left the hospital in good health, others were still ill at the end of McClellan's notations. Eighteen of the thirty-eight children for whom outcomes were recorded either left the hospital in good health or were listed as continuing in good health at the end of McClellan's study. An additional seventeen were either not in perfect health or, as McClellan noted, 'continued badly' at the end of the study. Three of the children progressed to such a state that the use of the water was discontinued. The Foundling Hospital continued to administer the water from Powis Wells to children beyond the 1760s,

\footnotetext{
${ }^{30} \mathrm{SCM}, 27$ October 1759, LMA, A/FH/A/03/005/003.

${ }^{31}$ Buchan, Cautions Concerning Cold Bathing, op. cit. (note 29), 16; Coley, 'Cures Without Care', op. cit. (note 10), 199; Harley, 'A sword in a madman's hand', op. cit. (note 10), 52.

32 In one child's case, the two conditions were combined.

33 Smallpox, measles, and whooping cough were the conditions singled out in the General Registers.

34 The sub-committee noted in 1759 that 'the children in general seem to be extremely subject to distempered eyes' and ordered that the nurses be directed not to expose the children to strong light. The following week the committee also mandated that hats and bonnets be provided for children with weak eyes since, 'the evil arises from their being exposed to a bleak North and North East wind without any covering to their heads for Shelter for the Eyes': SCM, 15 September 1759, LMA, A/FH/A/03/005/003.

35 SCM, 7 June 1760, LMA, A/FH/A/03/005/004.
} 
indicating the continued prevalence of the widespread perception that mineral water was a potentially effective treatment for a variety of ailments. It may also have reflected a recognition, based on McClellan's case study, that the water was useful in some cases and harmful in almost none and could, therefore, be considered an appropriately mild treatment suitable for use on children.

McClellan's study of Powis Wells water is significant in several respects. First, it highlights the importance of institutional settings in providing practitioners with access to large numbers of children, upon whom new methods of treatment could more easily be tested without, in this instance at least, the need for the consent and co-operation of parents. Second, in McClellan's case, the institution itself was also crucial in initiating and overseeing the study, indicating that co-operation between practitioners and institutional administrations could encourage advances in medical treatments for children. Lastly, McClellan's study was well-organised, and the details and progress of the treatment were well documented. While this aspect of the study may have been, at least in part, the result of the larger efforts of the Foundling Hospital administrators to keep meticulous records, it also reflected a desire to test a treatment on a set group of children, and to observe the results in a somewhat systematic manner. McClellan did not administer the mineral water to the children on an ad hoc basis. He kept detailed records of how the children responded to the treatment over time. McClellan's approach indicates that this particular study, much like the case of Thomasine Edmonton, was intended to expand medical knowledge of a particular treatment as it related to child patients. As mentioned earlier, McClellan spent almost his entire medical career working as an apothecary to the Foundling Hospital. Aside from the odd nurse or hospital servant, the bulk of his patients in these years were children. When considered within the context of McClellan's medical practice, his interest in children's health and in the progress of the Powis Wells study is clearly evident. Both McClellan and the Foundling Hospital administration clearly felt that children's conditions could and should be managed medically, and that such a study, headed by a medical practitioner, could contribute a fresh approach to the problems of providing medical treatment for children.

\section{William Watson and the Use of Electricity}

Many of the functions served by McClellan's study can also be observed in a single case study conducted by William Watson, physician to the Foundling Hospital from 1762 to 1787. Though Watson continued to publish works on botany throughout his career, he was widely reputed for his work on electricity, which he began through experimentation in 1744. Nineteen years later, Watson published an account of his attempt to use electricity to treat paralysis in a young Foundling Hospital girl. Since, in this instance, Watson was only providing assistance to a single patient, his study differs somewhat from that of McClellan. Yet it possible to see in the two cases similar motivations at work. Watson, like McClellan, spent several years serving the Foundling Hospital and, like McClellan, he was eager to investigate any new means of curing the conditions he witnessed in his child patients. The way in which Watson documented his case also bore some resemblance to McClellan's attempt to record all relevant data, thereby lending credence and authority to an innovative approach that was still being tried and tested by other practitioners of the time.

On 10 July 1762, when Catherine Field was approximately six or seven years of age, she was admitted to one of the Foundling Hospital's infirmaries with a fever. ${ }^{36}$ The

${ }^{36}$ Weekly reports on the sick in the infirmaries, January 1761-April 1763, LMA, A/FH/A/18/005/001. 
following week her condition had altered to 'fever and lock'd jaw'. She remained in the infirmary until 19 February 1763, suffering from 'universal rigidity', 'lock'd jaw and universal rigidity', 'partial rigidity' and finally, in her last week, smallpox. When Watson visited Catherine in the infirmary along with Dr Charles Morton, also a physician to the Foundling Hospital, they concluded, 'from her offensive breath and other indications, that the spasm of her jaw was symptomatic, either of worms or foul bowels' ${ }^{37}$ Over the next three weeks her pulse was taken at intervals and a regimen was prescribed, though she continued to be feverish and the rigidity progressed to her neck and back until by the end of September, almost all the muscles of her body were rigid and motionless' ${ }^{38}$ As her condition deteriorated, Watson and Morton attempted a series of treatments including: warm bathing and then cold bathing, linseed oil and other medicines to destroy the worms and cleanse the bowels, bleeding with leeches at the temples to reduce the fever, blisters on various parts of the body, and more than nine hundred drops of 'Tinctura Thebaica', an opiate. ${ }^{39}$ Medical treatments were suspended from the end of September 1762, though Watson noted 'dreadful however as her situation was, she was still alive: we were desirous therefore of omitting nothing, that in the least might be expected to relieve her'. ${ }^{40}$

From this point, they began to attempt the use of electricity to contract her muscles. From the middle of November 1762, Catherine was electrified every day, or every other day, for approximately twenty minutes. Her convulsions ceased after about a fortnight and her muscles had fully loosened by the end of January 1763, and 'she could not only stand upright, but walk, and [could] even run like other children of her age'. ${ }^{41}$ Catherine Field was presented before the governors of the Foundling Hospital who, according to Watson, expressed amazement at her recovery. Indeed, her health had improved enough for her to be apprenticed only two years later. In September 1765 Watson again attempted an electric treatment on a Foundling Hospital child listed as 'paralytic'. This child, Sarah Parker, was treated with electricity twice a week from 14 September 1765 to 19 April $1766 .{ }^{42}$ The evidence of this second case indicates that, following the case of Catherine Field, the governors of the hospital were receptive to the use of electricity on children, and that they were willing to make use of a treatment that was still being tested in the medical and scientific community.

Watson's treatment of Catherine Field occurred at a time of optimism within the medical community about the possibilities of electricity. The use of electricity in medical contexts had gained several strong advocates by the time that Watson was involved in Catherine Field's case. ${ }^{43}$ The ninth edition of John Wesley's Primitive Physic, published in 1761, contained the first recommendation for the use of electricity in the popular text. ${ }^{44}$ Medical institutions, in particular, played a role in the testing and legitimisation of medical electricity, since they were 'centres for practical experimentation with novel therapies' ${ }^{45}$

\footnotetext{
37 William Watson, 'Observations Upon the Effects of Electricity Applied to a Tetanus, or Muscular Rigidity, of Four Months Continuance. In a Letter to the Royal Society', Philosophical Transactions, 53 (1763), 10-26.

38 Ibid., 12.

${ }^{39}$ Ibid., 14

${ }^{40}$ Ibid., 15.

41 Ibid., 17.

42 Weekly Reports of the Sick in the Infirmaries, April 1766, LMA, A/FH/A/18/005/002.

${ }^{43}$ Schaffer, 'The consuming flame', op. cit. (note 10), 490.

${ }^{44}$ Deborah Madden, 'A Cheap, Safe and Natural Medicine': Religion, Medicine and Culture in John Wesley's 'Primitive Physic' (Amsterdam: Editions Rodopi, 2007), 3.

${ }^{45}$ Elliott, “"More Subtle Than the Electric Aura”, op. cit. (note 10), 201.
} 
Electricity enjoyed wide popularity in part because it had a dual appeal. To the wealthy and educated, electrical displays, like James Graham's celestial bed, were novelties, popular demonstrations of Newtonian experimental philosophy. ${ }^{46}$ To the lower orders the aspects of novelty and spectacle may have been similar but the cheapness and universality of electricity allowed its advocates to advertise it as a useful medical therapy for the poor, a factor which no doubt influenced the desire of institutions to test electricity as a cheap and potentially useful treatment. ${ }^{47}$

However, the fact that electricity was in vogue during the 1760 s does not fully explain Watson's approach to Catherine Field's case. Watson was clearly aware that the electric treatment prescribed in this case was unorthodox. His 1746 publication marked him as a sceptic of electricity's applicability to medicine, and his use of electricity was always cautious. In 1758 he recorded a case in which he tried an electrical cure on a young woman who was afflicted with convulsions. ${ }^{48}$ In this particular case, he suspended electrical treatments when they appeared to exacerbate the convulsions. He chose instead to, in his words, 'trust the whole to time'. ${ }^{49}$ Watson was clearly willing to try electricity when he felt it might effect an improvement in a patient, but he was also careful to choose the right conditions to test the efficacy of electricity. He was not willing to risk the patient's health simply to attempt an innovative approach. Significantly, he was also eager to justify his actions to the medical community through print. It is obvious that he recognised the unorthodox nature of the treatment and, while part of his intention in publishing was to highlight the success of his methods, his tone also reflected a desire to record his experience, and to make other medical practitioners aware of a potentially beneficial treatment.

While this was quite obviously not a modern clinical trial, Watson's intent in trying electricity, and then publishing his success with the new method, carried many of the same motivations: to try a new treatment, to justify the procedure used in a publication, and to acquaint the medical community with a new method which could improve or even save the lives of future patients. It is also clear that Watson saw Catherine Field's case as a type of experiment. In his 1763 letter to the Royal Society, he defended the procedure he used in the case of Catherine Field as a true test of the benefits of electricity since other cures had had no effect on the girl's condition, noting 'the patient under electrifying only, and that at a very severe season of the year, has been restored to perfect health, I cannot refuse my assent in believing it effected by the power of electricity, ${ }^{50}$

\section{George Armstrong and the Use of Hemlock for Whooping Cough}

The trials of mineral waters and electricity conducted at the Foundling Hospital by McClellan and Watson provoked little negative comment, at least in print. Though McClellan's trial was never published, Watson's appeared in a widely read journal, and certainly could have motivated discussion. McClellan's trial could also have aroused criticism from the Foundling Hospital's medical or administrative staff, or from the many

\footnotetext{
${ }^{46}$ Roy Porter, Health for Sale: Quackery in England, 1660-1850 (Manchester: Manchester University Press, 1989), 157-72.

${ }^{47}$ Bertucci, 'Therapeutic attractions', op. cit. (note 10), 276.

48 William Watson, 'An Account of Some Extraordinary Effects Arising from Convulsions: Being Part of a Letter to John Huxham. . ', Philosophical Transactions (1683-1775), 50 (1757-1758), 743-5.

${ }^{49}$ Ibid., 745.

${ }^{50}$ Watson, 'Observations Upon the Effects of Electricity', op. cit. (note 37), 19.
} 
medical men who served as governors of the institution. Most likely, it was the relatively successful nature of both trials that was crucial in precluding any negative backlash. Such was not the case with George Armstrong's efforts to popularise the use of hemlock as a treatment for infants suffering from whooping cough. In this case, innovative medical practice involving children was perceived as excessively dangerous, carrying a risk which did not justify the use of a new treatment. As such, Armstrong's trials provide a useful counterpoint to those initiated by McClellan and Watson, as well as evidence that, while the medical community was eager to develop new methods of preventing infant and child mortality, they were not willing to countenance risky treatments, or improperly conducted trials.

Until 1772 Armstrong treated whooping cough with antimonial vomits. ${ }^{51}$ However, following the publication of a treatise by William Butter, he began to experiment with the use of hemlock. In A Treatise on the Kinkcough, William Butter, an Edinburgh-trained physician who also published works on fever and angina pectoris, recommended treating whooping cough using hemlock mixed in liquid, usually spring water, occasionally with lemon juice, sugar, or other additives. ${ }^{52}$ By 1777 George Armstrong had, using a combined treatment programme of hemlock, bleeding, antimonial solutions, and purges, treated 357 children suffering from whooping cough, of whom he reported seventeen dead. ${ }^{53}$ In the 1783 edition of his publication on the diseases of infants, the number of whooping cough cases treated with hemlock had risen to 732 , of whom he reported only twenty-five dead. ${ }^{54}$ All of these child patients were seen by Armstrong at the Dispensary for the Infant Poor, which he had founded in 1769, and which he operated on an almost solitary basis.

In 1777, Armstrong's reputation, as well as the reputation of his dispensary, was threatened when John Coakley Lettsom accused Armstrong in the Gentleman's Magazine of experimenting with hemlock in an indiscriminate and dangerous fashion on the dispensary children, citing Armstrong's 'warm disposition to try experiments in a very serious and dangerous disease'. ${ }^{55}$ In his memoirs of the General Dispensary, Lettsom noted of Butter's recommendation of the use of hemlock in cases of whooping cough, 'we find no very evident instance of its success related by its patron; and therefore, since the perusal of his own cases, I have never attempted his hemlock' ${ }^{56}$ Lettsom's accusations against Armstrong were grounded in the argument that other, safer remedies for whooping

${ }^{51}$ George Armstrong, An Essay on the Diseases Most Fatal to Infants. To which are Added Rules to be Observed in the Nursing of Children; With a Particular View to Those Who Are Brought Up by Hand (London 1767), 91-4.

52 William Butter, A Treatise on the Kinkcough With an Appendix, Containing an Account of Hemlock, and its Preparations (London 1773), 164; G.T. Bettany, 'Butter, William (bap. 1726, d. 1805)', rev. Claire L. Nutt, Oxford Dictionary of National Biography (Oxford: Oxford University Press, 2004), available online at http:// www.oxforddnb.com/view/article/4225 (accessed 14 October 2008).

53 George Armstrong, An Account of the Diseases Most Incident to Children, From Their Birth Till the Age of Puberty; With a Successful Method of Treating Them. To Which is Added, an Essay on Nursing. Also, a General Account of the Dispensary for the Infant Poor, From its Institution in 1769, to the Present Time, 3rd edn (London, 1777), 107-19.

54 Whooping cough cases were not actually admitted to the dispensary. Parents and nurses were given medicines to administer to the children at home: George Armstrong, An Account of the Diseases Most Incident to Children, From the Birth Till the Age of Puberty; With a Successful Method of Treating Them. To Which is Added, an Essay on Nursing; With a Particular View to Children Who are Brought Up by Hand. Also a Short General Account of the Dispensary for the Infant Poor, 4th edn (London, 1783), 116, 191.

55 John Coakley Lettsom, 'Observations on some passages in Dr Armstrong's diseases of children', Gentleman's Magazine, 47 (September 1777), 416-8.

56 John Coakley Lettsom, Medical Memoirs of the General Dispensary in London, for Part of the Years 1773 and 1774 (London, 1774), 242; italics are Lettsom's. 
cough existed and should, therefore, be used in preference to hemlock. In 1772, the same year that Armstrong began the use of hemlock for whooping cough, John Haygarth reported on the use of tartar emetic as a treatment during a whooping cough epidemic in Liverpool. According to Haygarth, tartar emetic mitigated both the cough and fever and also had no taste, making it a useful remedy for children, especially young infants. ${ }^{57}$ William Buchan similarly argued that opium was superior to hemlock for the treatment of whooping cough and that hemlock could be dangerous and should be purchased already prepared in a shop, as opposed to relying on home preparation. ${ }^{58}$ Hemlock was first included in the pharmacopoeia prepared by the Royal College of Physicians in 1791 with the warning 'though long supposed more poisonous than was just, yet, taken in too large a quantity, it is certainly capable of producing pernicious effects' ${ }^{59}$ Clearly hemlock was widely considered to be a potentially dangerous substance. Armstrong's use of it, in preference to the antimonial wine he had previously administered to whooping cough cases, was thus confusing and objectionable to many of his contemporaries.

In his response to Lettsom's accusations, Armstrong took a defensive stance, attempting to efface his own culpability in using dangerous medicine on children. ${ }^{60}$ In addition to noting that a treatment should never be dismissed without a fair trial of its efficacy, Armstrong responded that the deaths of children through the use of hemlock might have been related to nothing more than the fact that the parents of the dispensary children were becoming more efficient in reporting the deaths of their children. Armstrong clearly felt that, while fatalities were regrettable, he was not solely to blame. He had merely attempted a new cure to a disease which posed a serious threat to infants and children. However, as will be discussed, Lettsom's quarrel was not with Armstrong's efforts to test a new treatment, but with Armstrong's assessment of the risks involved, and his failure to take quantitative results into account. Lettsom's accusation was grounded in the assumption that new medical treatments had to be proven scientifically before they could be used on a wider scale. Tied to these concerns were growing demands that medical institutions, and the actions of medical practitioners, be accountable to public scrutiny. As John Millar, physician to the Westminster General Dispensary, noted, 'it is not fit that individuals of any profession should prey on public calamity: error ought not to be sanctified by custom, nor concealed by mystery and reserve; nor the test of arithmetical calculation evaded' ${ }^{61}$ According to Lettsom, Armstrong's medical practice was clearly suspect because, though Armstrong did keep track of the number of cases treated, an appreciation of the number of fatalities caused by hemlock did not prompt him to alter his treatment. In short, Lettsom was querying the way in which innovative medical practice was conducted. The fact that Armstrong's patients were infants and children contributed, as far as Lettsom was concerned, an additional cause for criticism, suggesting that innovative medical practice, when applied to children, needed to conform to a different set of parameters. While these

\footnotetext{
57 John Haygarth, 'Observations on the Bills of Mortality in Chester, 1772', in Mortality in Pre-Industrial Times: The Contemporary Verdict, facs. edn (Farnborough: Gregg, 1973), 75.

58 William Buchan, Domestic Medicine: or, a Treatise on the Prevention and Cure of Diseases by Regimen and Simple Medicine, 2nd edn (London, 1772), 263, 430.

59 The Pharmacopoeia. Of the Royal College of Physicians of London. Translated into English, With Notes, Indexes of New Names, Preparations, \& c. \& c. ..., 5th edn (London, 1791), 20.

60 George Armstrong, 'Reply to Dr Lettsom's Observations on some Passages in Dr Armstrong's Diseases of Children', Gentleman's Magazine, 47 (1777), 633-5.

61 John Millar, Observations on the Practice in the Medical Department of the Westminster General Dispensary: Together with an Arithmetical Calculation of the Comparative Success of Various Establishments for the Relief of the Sick... (London, 1777), 7.
} 
parameters may have been met by McClellan and Watson, under the watchful eye of the Foundling Hospital administration, Armstrong, who operated his dispensary on a nearly solitary basis, clearly failed, in the eyes of Lettsom, to conform to expectations.

The print debate between Armstrong and Lettsom clearly highlighted some of the problems perceived by contemporaries to be inherent in the medical treatment of children by male medical practitioners. Eighteenth-century medical practitioners interested in children's health were frequently forced to confront the assumption, emanating from the laity as well as from other medical men, that mothers, nurses, and midwives, rather than medical practitioners, were the natural authorities on children's health. This state of affairs created a degree of self-consciousness among those practitioners who treated children. Essentially, there was a necessity for their medical treatment of child patients to be beyond reproach, so as to avoid accusations that they did not possess the proper qualities to care for children. When seen in this context, and in relation to the wider trend towards medical professionalisation, Lettsom's attack on Armstrong becomes fraught with greater meaning. Lettsom was an incredibly prolific writer who frequently cast himself in the role of public commentator, particularly on medical matters and in response to anything he regarded as quackery. In this respect he was part of a vocal anti-quack movement which championed medical professionalisation at the expense of irregulars who were cast as dangerous threats to the public. Armstrong's use of a risky remedy on infant patients when other, safer cures were at hand, configured Armstrong as a threat to those practitioners, like Lettsom, who hoped to see medical care of children become the province of responsible, knowledgeable, authoritative medical practitioners.

Armstrong's efforts to develop a new treatment for children clearly aroused controversy, but his trial with hemlock should not necessarily be viewed as a failure. If nothing else, the controversy itself aroused the interest of other practitioners, as well as the literate public who read the Gentleman's Magazine. Armstrong's hemlock trial also demonstrated the potential for institutional spaces to provide opportunities to formulate new approaches to medical practice. In his dispensary, Armstrong had access to large numbers of children and, while he did not enjoy the same ability to observe the children over longer periods of time as did McClellan and Watson, the institution itself provided a useful space for the testing of a new treatment which, though partially unsuccessful, did, in the long term, serve the interests of medical authority over children's health by demonstrating to the public that the medical community was attempting to develop new approaches to children's health, and that the community would police itself from within to ensure that innovative medical practice involving children did not shade into dangerous territory.

\section{Conclusion}

This article began with a discussion of Thomasine Edmonton, a Foundling Hospital child who was sent to the Lock Hospital to be treated for venereal disease. The details of Thomasine Edmonton's life are tragic, but in many ways unremarkable. She died at a young age as the result of disease, like so many of her contemporaries. Yet as the first child to be treated through a formal partnership between the Lock Hospital and the Foundling Hospital, her case is representative of an increase in medical efforts to utilise institutions to come to new understandings of how disease in children could be combated. The case of Thomasine Edmonton, like that of Catherine Field, and the children in McClellan's and Armstrong's studies, clearly demonstrates that institutions were important spaces for medical practitioners to confront child patients, and for therapeutic practices related to children to be formulated. These encounters between medical practitioners and child 
patients helped to demonstrate to the public and to the rest of the medical community that medical practitioners could treat child patients, that children could benefit from an innovative approach to medical practice, and, as a consequence, that children required the attention of medical practitioners. In turn, these practitioners increasingly considered themselves to be the only individuals fully qualified, not merely treat children, but to advance knowledge of children's health to the point that future children stood to benefit. The therapeutic trials discussed here provide clear evidence of how eighteenth-century medical practitioners struggled to understand the diseases of children, how they adapted a general spirit of innovation and the methods of quantification to do so, how they devoted time and energy to their child patients, and how they gradually, and with many, many setbacks, worked to establish themselves as authorities on the subject of children's health. 